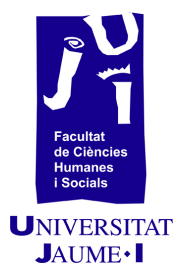

\title{
La performatividad del diseño gráfico en busca de justicia e igualdad social
}

Rosa del Carmen Castañeda Peñaloza Rosy.castanedap@gmail.com

María de las Mercedes Portilla Luja invposgradofad@gmail.com 


\section{Resumen}

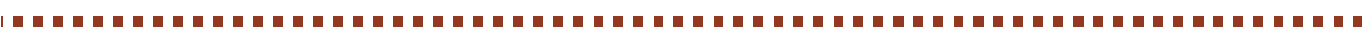

El presente texto tiene como finalidad reflexionar y comprender la performatividad del diseño gráfico en proyectos para contribuir con la justicia e igualdad social, a partir de herramientas que sean innovadoras, multidisciplinario e interdisciplinarias y que respondan a las verdaderas necesidades de la sociedad. Es evidente que las formas de comunicación han ido cambiando; por ello es necesario desarrollar acciones de comunicación de orden estratégico que permitan comunicarse de forma más eficaz y viral para dar a conocer las situaciones de injusticia social a partir de la innovación comunicativa, apelando a la razón de participación para promover la igualdad.

El diseño gráfico conceptualiza ideas, contribuye a reforzar y fomentar valores dentro de la vida social; la intencionalidad al diseñar debe ser pensada para la transformación y el cambio social; sin duda, el diseño tiene la capacidad de influir en la conducta del espectador, mas allá de persuadir, lo que se busca es disuadir comportamientos arraigados que no contribuyan a un bien común y de esta manera propiciar que el cambio provenga de la convicción de los individuos y no de la imposición.

Palabras clave: diseño gráfico, comunicación, performatividad.

\section{Introducción, material y método}

El filósofo Austin (1990) propuso el concepto de performatividad, que establece una obligada conexión entre lenguaje y acción. Para Austin, la performatividad se da cuando en un acto del habla o de comunicación no solo se usa la palabra sino que esta implica forzosamente a la par una acción. Es imprescindible que la acción performativa del discurso del diseño gráfico sea una acción de transformación que impacte en la sociedad con la finalidad de contribuir a soluciones $y$, por ende, elevar la calidad de vida de las personas.

La performatividad es un proceso que implica la configuración de nuestra actuación en maneras que no siempre comprendemos del todo, y actuando en formas políticamente consecuentes (Butler, 2009: 335).

El discurso del diseño gráfico es performativo desde la perspectiva social y en relación con los diversos temas, dado que no se enfoca solo en las nociones de esta índole sino que va mas allá, implicando acciones a favor de ellas. Ledesma (2010) menciona que el diseño no solo es un generador de reflexiones y de pensamiento 
sino de acciones; esto lo clasifica en sus funciones: hacer-leer, hacersaber y hacer-hacer. Esto nos muestra la performatividad del diseño gráfico, y cumple la función básica de hacer legible y entendible un mensaje sintetizando un discurso en ideas concretas para generar acciones transformadoras.

Ledesma (2010) lleva esta noción al modelo del triangulo performativo en cual establece el hacer-hacer como una forma de persuasión con la intención de modificar las conductas de los destinatarios, de forma que es la búsqueda de nuevas adhesiones o bien de refuerzo de las ya existentes. Sin embargo, Kaplún (2002) rechaza la comunicación persuasiva como comunicación educativa; establece que la comunicación persuasiva busca dirigir comportamientos en los individuos, dejando de lado el diálogo, puesto que el individuo se centra solo en oír y memorizar, por lo que en determinado tiempo se olvida y el efecto desaparece. Sin embargo, si se trabajara más en una comunicación educativa, el resultado sería más favorable: el educando se apropiaría del conocimiento, pasaría de ser un educando-oyente a ser un educando-hablante.

De acuerdo con lo anterior, podemos situar el diseño considerando sus posibilidades discursivas desde la dimensión de su función social, ya que la actividad diseñística tiene un impacto social y cultural que conlleva que los objetos diseñados cuentan con una carga simbólica que resulta de las relaciones establecidas desde los contextos social y cultural en los que se desenvuelven y que al mismo tiempo exige una reflexión, al tener la intención de despertar la conciencia y el pensamiento objetivo en un acto de responsabilidad hacia, por y para la sociedad.

El diseño gráfico es capaz de generar una reacción deseable de transformación. Frascara (2000) menciona que el diseño y la producción de comunicaciones están dirigidas a afectar el conocimiento, las actitudes y el comportamiento de la gente, por lo que el diseño es capaz de construir diversos productos de un modo u otro que satisfaga las expectativas de la gente; es el conjunto de estrategias que se centra en generar cambios, aceptación y dar a conocer los problemas a los que nos enfrentamos día a día.

Se pueden modificar actitudes que incluso estén profundamente arraigadas desde los patrones referenciales del colectivo al que pertenece el individuo; es evidente el trabajo multidisciplinario e interdisciplinario desde los diferentes ámbitos del conocimiento como las ciencias sociales y las humanidades, por lo que en este sentido el trabajo del diseñador gráfico es fundamental. El diseño es una actividad que se enfoca en configurar el entorno artificial y construye elementos significativos, al tiempo que genera la interacción entre el objeto, el individuo y la sociedad; en esencia, es el impulso proyectual y creativo; así pues, desde su función social 
determina el objetivo de contribuir a soluciones y elevar la calidad de vida.

A través del diseño podemos educar visualmente a nuestra sociedad, desde nuestras el diseño y la comunicación ejercemos diferentes didácticas, en cuanto a los mensajes, ideas y creaciones. Kaplún (2002) menciona que el comunicador es una especie de arquitecto de la conducta y reafirma diferentes posturas que señalan que la comunicación puede modificar el comportamiento, las conductas y las formas de pensar de los individuos.

El diseño concibe a los individuos para los que diseña como individuos dinámicos que reaccionan y que pueden cambiar situaciones, el diseño trabaja para todo individuo teniendo en cuenta factores económicos, sociales y medioambientales, por lo que se puede considerar el diseño socialmente responsable, como aquel que se preocupa por una sociedad más justa.

La responsabilidad social es un tema que ha desarrollado su importancia frente al mundo en el que vivimos, frente a los problemas a los que nos enfrentamos como parte de una sociedad en la que nos desarrollamos y por ello es necesario atender a su relevancia y alcance. En términos generales la responsabilidad social es reconocer y aceptar los compromisos que como individuos tenemos con la sociedad y el medio, es ser conscientes y sensibles, de forma colectiva o individual. Bedolla (2014) nos menciona que desde el diseño es necesaria la práctica de la responsabilidad social, de tal manera que los diseños se orienten hacia las personas que aporten un beneficio adicional, que no sean solamente la representación en una transición de compraventa.

La labor profesional del diseño se debe valorar desde su complejidad, ya que, en esencia, el trabajo se debe considerar como el resultado del análisis y del estudio de las necesidades propias de la sociedad, además de contribuir eficientemente a la mejora de las condiciones de vida de los seres humanos que habitan un determinado sector social.

Como se ha mencionado en varias ocasiones en el proyecto, el diseño gráfico es, sin duda, el medio ideal de difusión y de acción social para la transformación; asimismo, tiene la capacidad de trabajar como un agente de cambio, y tiene como motivación principal crear movilización social, impactar y activar a la mayoría de los individuos que pudiesen estar relacionados directamente e indirectamente con la causa. Es crucial determinar la importancia que conlleva la creación de movimientos sociales, que si son pasivos se vuelvan activos ante la causa y se configure una solidaridad activa. Por ello, es necesaria la investigación de la zona geográfica, la cultura, los comportamientos, los aspectos históricos, así como el análisis del macroentorno y del microentorno. 
Esta propuesta se centra en la movilización social desde una planificación estratégica de comunicación, a través de los objetivos para el cambio social, estableciendo todos aquellos aspectos que se considera imprescindible investigar, analizar y reflexionar. Asimismo, también es importante la forma en la que se comunicará el mensaje, la intencionalidad, el seguimiento, la evaluación y la reflexión.

[...] La forma en que las ideas y realidades sociales se representan influye en el modo en que las personas piensan en ellas, se relacionan con ellas y actúan en consecuencia. En otras palabras, la retórica está estrechamente vinculada al modo en que los públicos piensan sobre los temas y las personas de las que habla la comunicación de las ONGD, por lo que puede jugar un papel crucial en sus comportamientos. Los discursos públicos son formas de educación informal pues participan en la configuración de la esfera pública y de los imaginarios por los que se rige (Nos Aldás, Iranzo y Frané, 2012: 214).

Álvarez (2003) ofrece algunos elementos de reflexión sobre las áreas metodológicas desde las que pudiese abordar la publicidad social y sus efectos sobre los individuos. Esta es un recurso que resulta interesante de indagar; Feliu (2004) la define como la promoción de ideas o actitudes no exclusivamente comerciales, campañas de interés público o de utilidad social; asimismo hace mención que a estas formas publicitarias se les han aplicado diferentes modalidades como publicidad de utilidad pública, publicidad de interés social, publicidad de bien público e incluso publicidad de causas sociales. En cierta manera se refriere a representaciones de comunicación sobre temas que están relacionados con problemáticas sociales.

Asimismo, es de suma importancia conocer las diferentes técnicas y herramientas que podrán ayudarnos a construir e implementar cualquier proyecto de diseño con fin social, identificar las fortalezas y debilidades de cada una nos permitirá construir una metodología acorde a las necesidades específicas y los objetivos establecidos. Está clara la existencia de diversas metodologías con el objetivo central de brindar un servicio o producto funcional $y$ estético, por lo que es sustancial comprender si alguna está construida para servicios o productos con fines sociales. Por consiguiente, este capítulo tiene como finalidad contrastar la implementación de las metodologías en el ámbito académico a partir del diseño y, a su vez, encontrar aquella metodología que pueda ser útil en el diseño de una campaña social.

Si bien es necesario ofrecer servicios y productos de calidad que brinden en conjunto la funcionalidad y lo estético, también lo es concienciar de que sea un diseño responsable, que busque satisfacer las verdaderas necesidades sociales. Por ello, la intención es abordar 
los temas hasta ahora, como la responsabilidad del diseñador gráfico ante la sociedad, establecer qué es un proyecto social, sus generalidades y sus necesidades, con la finalidad de correlacionar el conocimiento de diversas disciplinas y de esta manera lograr elevar la calidad de vida de todas aquellas personas, grupos o comunidades vulnerables.

Por lo tanto, los productos deben visualizarse también como objetos que permitan la reflexión y el pensamiento retomando la idea de que «[...] las creaciones de diseño son al mismo tiempo acontecimientos y síntomas sociales» (Badosa y Subirats, 2017: 37). En el mismo sentido, Potter (2009) define al diseñador como un sujeto que cambia los espacios, que genera objetos y construye mensajes; que hace lecturas de la realidad, las transforma y las reescribe, y por ello debe asumir nuevos roles, ser consciente de sus límites y las posibilidades reales para incidir en la transformación de la realidad social, considerando que no tiene en sus manos toda la responsabilidad sino que solo contribuye desde sus competencias.

Por ello, se hace énfasis en el enfoque respecto a la función social del diseño como "[...] la dimensión de una actividad cuya finalidad es garantizar la equidad por encima de los intereses individuales y disociantes, la ausencia de lucro privado o su recanalización hacia fines solidarios» (Chávez, 2001: 92).

Es evidente que el diseñador puede contribuir a la calidad de vida del ser humano a través de los objetos construidos lo que implica una gran responsabilidad social; el diseño gráfico tiene la capacidad de diseñar y no solo de reproducir, así esta da forma a las ideas que se convierten en mensajes -en un proceso de comunicación visual-, crea todo un discurso con un propósito específico y así lograr el impacto esperado. Es una profesión en evolución constante que sin duda se reinventa conforme a las necesidades sociales.

A través de su discurso podemos fomentar los derechos ciudadanos para lograr un mundo más justo. La justicia social ha sido un tema recurrente en los estudios de sociología, filosofía, economía y política; sin embargo, es un tema que compete al diseño gráfico como a cualquier área del conocimiento, puesto que forma parte del magma esencial de la educación social, cumpliendo con fundamentos de igualdad de oportunidades, derechos humanos y de justicia.

Asimismo, al abordar el diseño para contribuir a la justicia social e igualdad, no puede dejarse de lado la importancia que tienen en el contexto actual las directrices y acciones vinculadas directamente con los ODS planteados por la ONU con el compromiso de guiar la labor profesional en favor del desarrollo y, en particular, con los planteamientos actuales del desarrollo sostenible de la Agenda 2030, entre los que hay los siguientes: el fin de la pobreza, hambre cero, 
salud y bienestar, educación de calidad, equidad de género, agua limpia y saneamiento, energía asequible y no contaminante, trabajo decente y crecimiento económico, industria, innovación e infraestructura, reducción de las desigualdades, ciudades y comunidades sostenibles, producción y consumo responsables, acción por el clima, vida submarina, vida de ecosistemas terrestres, paz, justicia e instituciones sólidas así como las alianzas para lograr los objetivos.

De aquí la relevancia de hacer énfasis en que las problemáticas sociales son el reflejo de una realidad en la que intervienen aspectos multifactoriales y estas problemáticas, en definitiva, no han de ser resueltas si se abordan solamente desde una de sus aristas; la suma de esfuerzos debe realizarse desde todos los ámbitos posibles una vez que se es consciente de la necesidad de hacerlo, por lo que el diseñador debe asumir este reto e involucrarse en proyectos de alto valor social.

Con lo anterior podemos comprender que el diseño gráfico significa mucho más que solo crear imágenes; significa comunicar y educar mediante mensajes visuales de forma efectiva. Por eso es importante conocer los diferentes recursos, para combinarlos de forma correcta y adecuada para elaborar un discurso transformador que eduque a la sociedad en busca de un bien social, que es un bien comunitario y funcional donde una parte del sector requiere satisfacer necesidades concretas que conformen su realidad.

Como el diseño gráfico es una herramienta fundamental en la educación de una sociedad en busca de justicia e igualdad, su participación tendrá que ser mayor en temas de violencia familiar, seguridad social, medio ambiente, desnutrición, desigualdad de género, maltrato animal, etc. $Y$ así promover proyectos e impulsar acciones que establezcan una sociedad más justa, que se sirva de los diferentes recursos, además de su constante transformación, puesto que las nuevas maneras de comunicación han ido cambiando y, por ende, las formas de hacer llegar los mensajes.

Es evidente que es necesario no seguir construyendo un mismo discurso solamente con la intencionalidad de persuadir, sino más bien hay que buscar todas las estrategias que puedan sustentar una comunicación más educativa. Existe la necesidad de educar a la sociedad sobre los problemas sociales a los que nos enfrentamos, debemos buscar el dialogo entre ambas partes, lograr cambiar la historia, quizás esta cuestión de estrategia nos solicita un poco más de imaginación y creatividad, ya que es un desafío en el que los comunicadores aportamos nuestros conocimientos y lo hagamos nuestro. 


\section{Conclusiones}

El discurso del diseño gráfico trasciende las necesidades comerciales por lo que debe ser más comprometido y crítico en cuanto al rol que ocupa en la sociedad sin dejar de lado los fundamentos de la profesión. El diseño es una herramienta fundamental dentro de la gestión de proyectos orientados a vender, pero debe impulsarse para contribuir a soluciones sociales; es el quehacer diario y el compromiso que tenemos como profesionistas hacia los problemas que nos competen dentro del contexto en el que nos desarrollamos.

El diseñador representa la concepción que el emisor tiene de la realidad de la que habla, de su relación con la misma y de la reacción que busca en la sociedad. El emisor, entendido como el agente de cambio, debe ser consciente de que la construcción de una campaña con fin social requiere constancia y tiempo suficiente de planificación; uno de los factores principales a considerar debería ser la investigación sobre lo que se quiere decir, al mismo tiempo que la forma en lo que se va a decir, puesto que ambas circunstancias son importantes. Es evidente que lo que se va a decir constituye el ser de la campaña en determinado contexto, pero la forma en la que se hará determina en buena medida el éxito o el fracaso de la campaña.

La performatividad del diseño gráfico debe ser de transformación en busca de igualdad y de justicia social, con la finalidad de contribuir a la calidad de vida de los individuos. Como comunicadores nos debemos preocupar por los problemas a los que se enfrenta la sociedad a la que pertenecemos, entender nuestra responsabilidad, participar más en proyectos de esta índole y así reflexionar el compromiso de diseñar para un impacto positivo $y$ efectivo.

Sin duda, el diseño gráfico es el vehículo a través del cual podemos transmitir mensajes, aunque pareciera que fuesen meramente acciones para crear consumo. Sin embargo, debemos comprender que el diseño es un medio para denunciar e informar sobre los problemas que nos competen a todos como individuos, como parte de un contexto, a través del diseño podemos concientizar, sensibilizar, informar y hacer participe a la sociedad para generar cambios sociales y contribuir a elevar la calidad de vida.

La performatividad del diseño gráfico debe ser pensada con la intencionalidad de transformación; se debe preocupar por cómo y con qué se diseña; considerar los efectos sociales, económicos, culturales y ambientales; su performatividad debe caracterizarse por su actitud de respeto y de servicio por el bien común, así como por la promoción de proyectos que propicien e incentiven acciones en busca de igualdad y justicia social, el respeto por los derechos humanos y la apelación a la participación ciudadana. 


\section{Bibliografía}

Álvarez, Antón. 2003. La publicidad en el Tercer Sector. Tendencias y perspectivas de la comunicación solidaria. Barcelona: Icaria.

Austin, John Langshaw. 1990. Cómo hacer cosas con palabras: palabras y acciones. Barcelona: Paidós.

Badosa, Jaume y Joan Subirats. 2017. «¿Qué diseño para qué sociedad? Notas sobre la funcionalidad social del diseño». Temes de Disseny 24: 23-41. Acceso en julio de 2017. https://www.raco.cat/index.php/Temes/article/view/76581

Bedolla Pereda, Deyanira. 2014. «El diseño y su responsabilidad para el desarrollo social y los consumos culturales». Memorias del Coloquio Internacional de Diseño, 1-3 de octubre. Toluca: Universidad Autónoma del Estado de México. http://coloquiodedise- no.faduaemex.org/2014/23.html.

Butler, Judith. 2009. "Performatividad, precariedad y políticas sexuales». AIBR. Revista de Antropología Iberoamericana 4 (3): 321-336.

Chávez, Norberto. 2001. El oficio de diseñar. Propuesta a la conciencia crítica de los que comienzan. Barcelona: Gustavo Gilli.

Feliu, Emilio. 2004. "La publicidad social». En Información, producción y creatividad en la comunicación, editado por Juan Benavides Delgado, Elena Fernández Blanco y David Alameda, 659-672. Madrid: Edipo. Fundación General de la Universidad Complutense de Madrid. Acceso del 26 de octubre de 2017. http://rua.ua.es/dspace/handle/10045/15710.

Frascara, Jorge. 2000. Diseño gráfico para la gente. Buenos Aires: Infinito.

IDEO. 2017. «About ideo». Ideo. Acceso del 4 de septiembre de 2017. http://www.ideo.com/about.

Kaplún, Mario. 2002. Una pedagogía de la comunicación (el comunicador popular). La Habana: Caminos.

Ledesma, María. 2003. El diseño gráfico, una voz publica de la comunicación visual en la era del individualismo. Buenos Aires: Argonauta.

Nos Aldás, Eloísa, Amador Iranzo y Alessandra Frané. 2012. «La eficacia cultural de la comunicación de las ONGD: Los discursos de los movimientos sociales actuales como revisión». Comunicación, cambio social y desarrollo 17: 209-237. Acceso del 20 de agosto de 2017. https://revistas.ucm.es/index.php/CIYC/article/viewFile/39265/ 37848. 
Potter, Norman. 1999. Qué es un diseñador: objetos, lugares, mensajes. Barcelona: Paidós. 